\title{
Validation of an Arabic Version of the Adherence to Refills and Medications Scale (ARMS)
}

\author{
Ghaida Alammari ${ }^{1,+}$, Hawazin Alhazzani ${ }^{1}$, Nouf AlRajhi ${ }^{1}$, Ibrahim Sales ${ }^{1}$ (D) Amr Jamal ${ }^{2}$ (D), Turky H. Almigbal ${ }^{2}$, \\ Mohammed A. Batais ${ }^{2}$, Yousif A. Asiri ${ }^{1}$ and Yazed AlRuthia $1,3, *,+\mathbb{D}$
}

1 Department of Clinical Pharmacy, College of Pharmacy, King Saud University, P.O. Box 2454, Riyadh 11451, Saudi Arabia; 435202385@student.ksu.edu.sa (G.A.); 435203505@student.ksu.edu.sa (H.A.); 436204108@student.ksu.edu.sa (N.A.); isales@ksu.edu.sa (I.S.); yasiri@KSU.EDU.SA (Y.A.A.)

2 Family and Community Medicine Department, College of Medicine, King Saud University, P.O. Box 3145, Riyadh 12372, Saudi Arabia; amrjamal@KSU.EDU.SA (A.J.); almogbal@yahoo.com (T.H.A.); drmohammed34@gmail.com (M.A.B.)

3 Pharmacoeconomics Research Unit, College of Pharmacy, King Saud University, P.O. Box 2454, Riyadh 11451, Saudi Arabia

* Correspondence: yazeed@ksu.edu.sa; Tel.: +966-114-677-483; Fax: +966-114-677-480

+ The first and last authors contributed equally to this work.

check for updates

Citation: Alammari, G.; Alhazzani, H.; AlRajhi, N.; Sales, I.; Jamal, A.; Almigbal, T.H.; Batais, M.A.; Asiri, Y.A.; AlRuthia, Y. Validation of an Arabic Version of the Adherence to Refills and Medications Scale (ARMS). Healthcare 2021, 9, 1430. https:// doi.org/10.3390/healthcare9111430

Academic Editors: Sara Garfield and Gaby Judah

Received: 23 August 2021

Accepted: 21 October 2021

Published: 24 October 202

Publisher's Note: MDPI stays neutra with regard to jurisdictional claims in published maps and institutional affiliations.

Copyright: (c) 2021 by the authors. Licensee MDPI, Basel, Switzerland. This article is an open access article distributed under the terms and conditions of the Creative Commons Attribution (CC BY) license (https:// creativecommons.org/licenses/by/ $4.0 /)$.

\begin{abstract}
Background: Medication non-adherence is a complex multifactorial phenomenon impacting patients with various health conditions worldwide. Therefore, its detection can improve patient outcomes and minimize the risk of adverse consequences. Even though multiple self-reported medication adherence assessment scales are available, very few of them exist in Arabic language. Therefore, the aim of this study was to validate a newly translated Arabic version of the Adherence to Refills and Medications Scale (ARMS) among patients with chronic health conditions. Methods: This is a single-center cross-sectional study that was conducted between October 10th 2018 and March 23rd 2021. ARMS was first translated to Arabic using the forward-backward translation method. The translated scale was then piloted among 21 patients with chronic health conditions (e.g., diabetes, hypertension, etc. ... ) to examine its reliability and comprehensibility using the test-retest method. Thereafter, the Arabic-translated ARMS was self-administered to adult patients aged $\geq 18$ years with chronic health conditions visiting the primary care clinics of a university-affiliated tertiary care hospital in Riyadh, Saudi Arabia. Construct validity was examined using factor analysis with varimax rotation. Results: Of the 264 patients who were invited to participate, 202 (76.5\%) consented and completed the questionnaire. Most of the participants were males (69.9\%), married (75.2\%), having a college degree or higher $(50.9 \%)$, retired or unemployed $(65.2 \%)$, aged $\geq 50$ years $(65.2 \%)$, and are diabetic (95.9\%). The 12-item Arabic-translated ARMS mean score was $17.93 \pm 4.90$, and the scale yielded good internal consistency (Cronbach's alpha $=0.802$ ) and test-retest reliability (Intraclass correlation coefficient $=0.97$ ). Two factors were extracted explaining $100 \%$ of the of the total variance (factor $1=52.94 \%$ and factor $2=47.06 \%$ ). Conclusions: The 12 -item Arabic version of ARMS demonstrated good validity and reliability. Therefore, it should help in the detection of medication non-adherence among Arabic-speaking patient population and minimize the risk of adverse consequences.
\end{abstract}

Keywords: medication non-adherence; self-reports; validation studies; surveys and questionnaires; 12-item ARMS

\section{Introduction}

Medication non-adherence is a globally recognized multifactorial phenomenon impacting patients with various health conditions [1]. The World Health Organization (WHO) defines medication adherence as "the extent to which a person's behavior-taking medication, following a diet and/or executing lifestyle changes, corresponds with agreed 
recommendations from a health care provider." [1]. Its prevalence among patients with chronic health conditions in the developed countries was estimated to be as high as $50 \%$, and is believed to be higher in the developing countries [1,2]. In the United States, approximately half of patients with chronic illnesses are not believed to take their medications as prescribed resulting in over 100 billion United States dollars (USD) of avoidable healthcare costs [3,4]. Moreover, higher rates of hospital admissions and emergency department visits, disease progression, and poor clinical outcomes are believed to be direct consequences of poor medication adherence [3,5,6].

Even though multiple studies examined medication adherence among different patient populations worldwide, very few studies explored medication adherence levels among patients in the Middle East [7-10]. In Saudi Arabia, it was reported that up to $65 \%$ of patients with diabetes visiting primary care clinics in Al Hasa province are not adherent to their prescription medications [10]. Another questionnaire-based, cross-sectional, singlecenter study has estimated that $41.7 \%$ and $33 \%$ of patients with cardiovascular disease had medium and low levels of adherence to their prescription medications, respectively [9].

Multiple barriers to medication adherence have been identified in the literature [1]. Those barriers can be social (e.g., stigma associated mental illnesses) [11,12], economic factors (e.g., high copayments) [13], older age and polypharmacy [14], and poor health literacy [14]. Therefore, identifying reliable and efficient tools to assess medication adherence especially among patients with chronic health conditions became an area of research with great importance [15]. However, no gold standard medication adherence measure that can be relied upon exists so far due to the complexity of this phenomenon [16]. There are direct (e.g., face-to-face observation, and assessment of biological markers) and indirect (e.g., pill counts, and self-report questionnaires) medication adherence assessment methods with variable degrees of reliability and efficiency [16-19]. The direct medication adherence assessment tools are accurate to a great extent, however, they are somewhat invasive and impractical to use on a regular basis [19]. On the other hand, self-report questionnaires are non-invasive, less expensive, and easy to administer, albeit they are not as accurate as the direct assessment measures [20].

The studies that assessed medication adherence among Arabic-speaking patients have either used descriptive self-report questionnaires that have not been validated before or used the Arabic version of the 8-item Morisky Medication Adherence Scale (MMAS-8) which requires permission from the scale developer and administration fees [9,21]. Even though several other self-report medication adherence scales have been validated in different languages, such as Medication Adherence Questionnaire (MAQ), Brief Medication Questionnaire (BMQ), and Self-efficacy for Appropriate Medication Use Scale (SEAMS) [22-25], these scales have not been validated in Arabic.

The Adherence to Refills and Medications Scale (ARMS) is a 12-item widely used medication adherence assessment tool with proven reliability and validity among Englishspeaking patient population [26]. The scale was translated and validated in Turkish [27], Korean [28], Chinese [29] and Polish languages [30], among patients with chronic health conditions, such as diabetes and hypertension. However, this scale has not been validated among Arabic-speaking patients. Therefore, the aim of this study was to translate and validate ARMS into Arabic among Arabic-speaking patients with chronic health conditions.

\section{Methods}

\subsection{Study Design}

This was a single-center cross-sectional study that was conducted between October 10th 2018 and March 23rd 2021 at the primary care clinics of King Khalid University Hospital (KKUH) in Riyadh, Saudi Arabia. KKUH is a university-affiliated hospital providing primary and tertiary care to family members and relatives of King Saud University employees as well as citizens referred by the ministry of health. 


\subsection{Inclusion and Exclusion Criteria}

The study included Arabic speaking adult patients aged $\geq 18$ years with chronic health conditions (e.g., diabetes, hypertension, dyslipidemia, etc.) who regularly visit the primary care clinics at KKUH every six months, and have active electronic medical records (e.g., they are still eligible to receive care from the hospital). Patients without active electronic medical records, those whose native language is not Arabic, patients who do not fill their medications at KKUH pharmacy, and those with cognitive disabilities, such as dementia and Alzheimer's diseases, were excluded.

\subsection{Population and Data Source}

Two-hundred and sixty-four patients who met the inclusion criteria were identified by reviewing their electronic medical records and ensuring that they meet the inclusion criteria. Patients' health conditions are documented in text under the physicians' notes. Those patients were selected systematically by selecting every 10th patient from the electronic lists of patients scheduled for regular follow-up appointments with their primary care physicians between October 2018 and March 2021 in E-Sihi database, which is the electronic health system at KKUH. The patients were recruited by three pharmacy interns who were trained to recruit patients by following a standardized protocol specifying every step on how to approach patients, explaining the purpose of the study, and inviting them to participate by asking for their consent prior to inclusion in the study.

\subsection{Research Instrument Translation and Validation}

ARMS is a 12-item self-reported medication adherence scale that was developed in English language, and consists of two subscales (adherence with filling medications and adherence with taking medications). The original scale consisted of 14 items, however, it was shortened based on the psychometric analysis conducted by the scale developers to ensure high internal consistency and reliability [26]. Adherence with filling medications subscale consists of four items, and the remaining eight items comprise the other subscale (adherence with taking medications). Each item is scored using a 4-point Likert-scale ( 1 = none, 2 = some, $3=$ most and $4=$ All). The ARMS can range from 12 to 48 with higher scores indicating poor adherence [26]. This scale has been validated among different patient populations with various chronic health conditions, such as diabetes and hypertension, and was translated to different languages [28-30]. Moreover, a score of $\geq 16$ was used as a cut-off point to categorize surveyed patients into non-adherent (e.g., $\geq 16$ ) and adherent (e.g., <16) [30].

In order to translate and validate the 12-item ARMS into Arabic, the permission to independently translate and validate the ARMS was obtained from the developers. Forwardbackward translation method was used to translate the ARMS into Arabic. Two authors whose native language is Arabic and are proficient in English language translated ARMS into Arabic. The first draft of the translated ARMS was then reviewed for its face and content validity before being checked by a certified English language translator. Backward translation was then conducted by a native English speaker who is proficient in Arabic language, and no major issues were noticed. The pre-final version of the Arabic-ARMS was then piloted among a group of 21 patients with chronic health conditions (e.g., diabetes, hypertension, and dyslipidemia) to check its comprehensibility. The same questionnaire, which takes 10 to $15 \mathrm{~min}$ to complete, was re-introduced to the same group of patients two weeks later to examine its reliability using the test-retest method. No major changes were made and the final Arabic-ARMS was administered to patients who fit the inclusion criteria (Appendix A).

\subsection{Study Variables}

Sociodemographic characteristics (e.g., age, gender, monthly income, marital status, employment status, educational level, and whether the patient is enrolled in a private health insurance) were abstracted in the questionnaire. Moreover, health literacy was 
assessed using the single item literacy screener (SILS) developed by Morris et al. [31], and was translated and validated into Arabic by Al-Jumaili et al. [32], The SILS enquires about the need of the surveyee for someone's help to read and understand medical or medicationrelated instructions with five possible responses on a Likert scale (1-never, 2- rarely, 3sometimes, 4- often, 5- always). Those who responded with "sometimes", "often", and "always" are believed to have marginal or limited health literacy, and those who responded with "never" or "rarely" are believed to have adequate health literacy [31,32]. On the other hand, the medical characteristics of the participants (e.g., chronic health conditions and number of prescription medications) were also collected from the patients' electronic health records.

\subsection{Sample Size Estimation}

Even though a sample of 100 participants is deemed sufficient to conduct most selfreported scales validation [33], the minimum sample size was estimated to be 192 subjects using GPower ${ }^{\circledR}$ software version 3.1 for a medium effect size (e.g., Cohen's $d=0.3$ ), $\alpha=0.05$, $\beta=0.2$, a power of $85 \%$. Therefore, a response rate of $72.73 \%$ out of the systematically created list of 264 patients who met the inclusion criteria needs to be attained. This sample size also ensures the minimum sample needed for principal component analysis using the item to response theory [34].

\subsection{Statistical Analysis}

Descriptive statistics using frequencies and percentages, and mean \pm standard deviation (SD) are shown for the participants' characteristics and the scores of the 12-item Arabic-ARMS, respectively. In order to examine the Arabic-ARMS construct validity, principal component analysis with varimax rotation was conducted. Factors with eigenvalues greater than one were extracted [35]. Basic confirmatory factor analysis was conducted alongside the root mean square error of approximation (RMSEA) and Bentler comparative fit index (CFI) to examine the goodness of fit. Models with good fit have RMSEA $\leq 0.06$ and CFI $\geq 0.9$ [36]. Kaiser-Meyer-Olkin (KMO) measure was used to ensure sampling adequacy to conduct factor analysis with values above 0.5 considered satisfactory [37]. The reliability was examined using Intraclass Correlation Coefficient (ICC) for the test-retest method, and Cronbach's alpha method. Scales with ICCs values above 0.8 [38,39] and a Cronbach's alpha above 0.7 are generally considered reliable [40]. Convergent validity was examined using the composite reliability with a cut-off point of $\geq 0.6$; whereas, the discriminant validity was ensured if the square root of the average variance extracted (AVE) is greater than the correlation coefficient between the different extracted factors [41,42]. Homogeneity was checked using item-total correlations, and Spearman's correlation coefficient (rho) was calculated to examine the association between the ARMS score and different sociodemographic and medical characteristics. All statistical analyses were conducted using SAS ${ }^{\circledR}$ version 9.4 (SAS institute, Cary, NC, USA).

\subsection{Ethical Approval}

The study protocol was approved by the ethics committee of King Saud University College of Medicine (E-19-3721), and all respondents verbally consented to participate in the study. No patient identifiers were collected and the data were anonymized and coded. The study adhered to the ethical principles of Helsinki declaration [43].

\section{Results}

\subsection{Participants' Characteristics}

Out of 264 patients who fit the inclusion criteria and were invited to participate, 202 patients $(76.5 \%)$ filled out the questionnaire (Figure 1). Most of the participants were males $(69.9 \%)$, married $(75.2 \%)$, having a college degree (e.g., a technical college diploma or bachelor's degree) or higher $(50.9 \%)$, retired or unemployed $(65.2 \%)$, aged $\geq 50$ years (65.2\%), and 40.1\% had a monthly income between 5000-10,000 SAR (USD 1333.33-USD 
2666.66) as shown in Table 1. With regard to the medical characteristics of the participants, the vast majority of them (96.4\%) had diabetes (e.g., 34.1\% with diabetes type I and $62.3 \%$ with diabetes type II), $48 \%$ had dyslipidemia, $40 \%$ had hypertension, and $10.4 \%$ had hypothyroidism. Approximately $58 \%$ of participants reported taking six or more medications and only $12.8 \%$ had medical insurance as shown in Table 2.

Patients are potentially eligible and kept their appointments

$$
N=264
$$

\begin{tabular}{|c|c|}
\hline 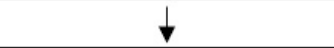 & $\downarrow$ \\
\hline $\begin{array}{l}\text { Agreed and verbally } \\
\text { consented to participate } \\
\qquad N=202\end{array}$ & $\begin{array}{l}\text { Patients who were excluded } \\
\text { from the study } \\
\qquad N=62\end{array}$ \\
\hline & $\begin{array}{l}\text { Reasons for exclusions: } \\
\text { - Duplicate medical } \\
\text { record numbers, } \\
\text { N= } 10 \\
\text { Withdrew from the } \\
\text { study, } N=\mathbf{2} \\
\text { Missing information, } \\
N=50\end{array}$ \\
\hline
\end{tabular}

Figure 1. Flowchart of patient recruitment.

Table 1. Study participants' sociodemographic characteristics $(n=202)$.

\begin{tabular}{lc}
\hline Gender & $141(69.8)$ \\
\hline Male & $61(30.2)$ \\
\hline Female & \\
\hline Age group (years) & $22(10.8)$ \\
\hline $18-25$ & $11(5.4)$ \\
\hline $26-33$ & $14(6.9)$ \\
\hline $34-41$ & $23(11.3)$ \\
\hline $42-49$ & $34(16.8)$ \\
\hline $50-57$ & $58(28.7)$ \\
\hline $58-65$ & $31(15.3)$ \\
\hline $66-73$ & $9(4.4)$ \\
\hline$\geq 74$ & $30(14.8)$ \\
\hline Marital status & $152(75.2)$ \\
\hline Single & $7(3.4)$ \\
\hline Married & $13(6.4)$ \\
\hline Divorced & \\
\hline Widowed &
\end{tabular}


Table 1. Cont.

\begin{tabular}{|c|c|}
\hline \multicolumn{2}{|l|}{ Educational level } \\
\hline No official education & $24(11.8)$ \\
\hline Completed few years of elementary school & $8(3.9)$ \\
\hline Elementary school diploma & $13(6.4)$ \\
\hline Middle school diploma & $15(7.4)$ \\
\hline Secondary school diploma or equivalent (industrial or commercial diplomas) & $39(19.3)$ \\
\hline Post-secondary school diploma or technical college & $15(7.4)$ \\
\hline University degree & $76(37.6)$ \\
\hline Graduate degree or equivalent (masters, doctorate, medical fellowship) & $12(5.9)$ \\
\hline \multicolumn{2}{|l|}{ Employment status } \\
\hline Government sector employee & $51(25.2)$ \\
\hline Private sector employee & $11(5.4)$ \\
\hline Freelancer & $8(3.9)$ \\
\hline Retired & $70(34.6)$ \\
\hline Unemployed & $62(30.6)$ \\
\hline \multicolumn{2}{|l|}{ Monthly income * } \\
\hline Less than 5000 & $49(24.2)$ \\
\hline $5000-10,000$ & $81(40.1)$ \\
\hline $10,000-15,000$ & $37(18.3)$ \\
\hline $15,000-20,000$ & $22(10.8)$ \\
\hline More than 20,000 & $13(6.4)$ \\
\hline \multicolumn{2}{|l|}{ Health literacy } \\
\hline Adequate & $160(79.2)$ \\
\hline Marginal $\backslash$ limited & $42(20.7)$ \\
\hline
\end{tabular}

* Presented in Saudi Arabian Riyals (3.75 SAR = 1 USD).

Table 2. Participants' medical characteristics $(n=202)$.

\begin{tabular}{lc}
\hline Number of Medications Taken & $14(6.9)$ \\
\hline One & $18(8.9)$ \\
\hline Two & $13(6.4)$ \\
\hline Three & $22(10.8)$ \\
\hline Four & $18(8.9)$ \\
\hline Five & $117(57.9)$ \\
\hline Six and more & $99(49.01)$ \\
\hline Chronic Diseases & $21(10.4)$ \\
\hline Hypertension & $12(5.9)$ \\
\hline Hypothyroidism & $97(48)$ \\
\hline Cardiovascular disease & $69(34.1)$ \\
\hline Dyslipidemia & $122(60.4)$ \\
\hline Diabetes mellitus type I & $4(1.9)$ \\
\hline Diabetes mellitus type II (no insulin use) &
\end{tabular}


Table 2. Cont.

\begin{tabular}{lc}
\hline Psychiatric disorders & $3(1.4)$ \\
\hline Pulmonary diseases & $15(7.4)$ \\
\hline Other & $26(12.9)$ \\
\hline Number of chronic health conditions & $113(55.94)$ \\
\hline $1-2$ & $80(39.60)$ \\
\hline $3-4$ & $9(4.45)$ \\
\hline $5-6$ & $26(12.8)$ \\
\hline Medical insurance & $176(87.1)$ \\
\hline Yes
\end{tabular}

\subsection{Reliability and Internal Consistency}

Using the test-retest method, the ICC for the Arabic-ARMS was 0.97 indicating good reliability. The item-total correlation coefficients for Arabic-ARMS ranged between 0.217 and 0.619 , and Cronbach's alpha values if each of the 12 items is removed ranged between 0.772 and 0.824 . Overall, the Arabic-ARMS demonstrated good internal consistency with a Cronbach's alpha of 0.802. The mean scores for the Arabic-ARMS 12 items alongside their standard deviation are shown in Table 3.

Table 3. Item Analysis of Arabic-ARMS.

\begin{tabular}{|c|c|c|c|}
\hline & Mean \pm SD & $\begin{array}{l}\text { Item-Total } \\
\text { Correlation }\end{array}$ & $\begin{array}{l}\text { Cronbach's Alpha if } \\
\text { Item Removed }\end{array}$ \\
\hline 1. How often do you forget to take your medicine? & $1.50 \pm 0.74$ & 0.510 & 0.78 \\
\hline 2. How often do you decide not to take your medicine? & $1.29 \pm 0.63$ & 0.532 & 0.78 \\
\hline 3. How often do you forget to get prescriptions filled? & $1.35 \pm 0.61$ & 0.473 & 0.78 \\
\hline 4. How often do you run out of medicine? & $1.72 \pm 0.89$ & 0.459 & 0.78 \\
\hline $\begin{array}{l}\text { 5. How often do you skip a dose of your medicine before you go to } \\
\text { the doctor? }\end{array}$ & $1.25 \pm 0.61$ & 0.524 & 0.78 \\
\hline 6. How often do you miss taking your medicine when you feel better? & $1.29 \pm 0.64$ & 0.529 & 0.78 \\
\hline 7. How often do you miss taking your medicine when you feel sick? & $1.31 \pm 0.74$ & 0.528 & 0.78 \\
\hline 8. How often do you miss taking your medicine when you are careless? & $1.28 \pm 0.65$ & 0.612 & 0.77 \\
\hline $\begin{array}{l}\text { 9. How often do you change the dose of your medicines to suit your } \\
\text { needs (like when you take more or less pills than you're supposed to)? }\end{array}$ & $1.66 \pm 0.78$ & 0.385 & 0.80 \\
\hline $\begin{array}{l}\text { 10. How often do you forget to take your medicine when you are } \\
\text { supposed to take it more than once a day? }\end{array}$ & $1.38 \pm 0.69$ & 0.572 & 0.77 \\
\hline $\begin{array}{l}\text { 11. How often do you put off refilling your medicines because they cost } \\
\text { too much money? }\end{array}$ & $1.58 \pm 0.82$ & 0.363 & 0.79 \\
\hline 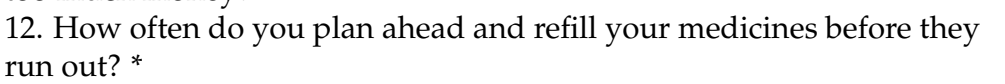 & $2.25 \pm 1.22$ & 0.217 & 0.82 \\
\hline
\end{tabular}

\footnotetext{
* This item was reverse-coded.
}

\subsection{Factor Analysis}

The KMO for sampling adequacy was 0.8 indicating sufficient sample to run factor analysis. Using principal components analysis with varimax rotation, two factors were revealed with eigenvalues greater than one as shown in Table 4 . The first factor (adherence with taking medications) consisted of eight items (e.g., item-1, item-2, item-5, item-6, item-7, item-8, item-9, and item-10) explaining 52.94\% of variance and having a mean score of 12.59 and a standard deviation of 3.92. On the other hand, the second factor (adherence with filling medications) consisted of four items (e.g., item-3, item-4, item-11, and item-12) explaining $47.06 \%$ of variance and having a mean score of 6.93 and a standard deviation of 2.19. The Cronbach's alpha values for the adherence with taking medications and 
adherence with filling medications subscales were 0.804 and 0.665 , respectively. The two extracted factors demonstrated goodness of fit using the confirmatory factor analysis with a CFI of 0.964 and RMSEA $<0.001$. The composite reliabilities for the first and second factors were 0.85 and 0.64 , respectively, which ensures the convergent validity. The root square of AVEs for factors one and two were 0.66 and 0.56 , which are higher than the correlation coefficient between the two factors (e.g., correlation coefficient $=0.499$ ) indicating good level of discriminant validity.

Table 4. Factor Analysis of the Arabic-ARMS (Varimax rotation method).

\begin{tabular}{lcc}
\hline & Factor 1 & Factor 2 \\
\hline \% variance explained & 52.94 \\
Items & 0.808 \\
1. How often do you forget to take your medicine? & 0.588 \\
2. How often do you decide not to take your medicine? & 0.607 \\
3. How often do you forget to get prescriptions filled? & 0.648 \\
4. How often do you run out of medicine? & 0.646 \\
5. How often do you skip a dose of your medicine before you go to the doctor? & 0.803 \\
6. How often do you miss taking your medicine when you feel better? & 0.338 \\
7. How often do you miss taking your medicine when you feel sick? & 0.337 \\
8. How often do you miss taking your medicine when you are careless? & 0.755 \\
9. How often do you change the dose of your medicines to suit your needs (like when you take & \\
more or less pills than you're supposed to)? & \\
10. How often do you forget to take your medicine when you are supposed to take it more than \\
once a day?
\end{tabular}

\subsection{Adherence Scores}

The mean \pm SD score of the Arabic-ARMS was $17.93 \pm 4.90$, and its median (Q1Q3) score was 17.00 (15.00-20.00). Using a score of $\geq 16$ as cut-off point to categorize participants into adherent (e.g., <16) and non-adherent (e.g., $\geq 16$ ), $36.14 \%$ of the participants were considered adherent and $63.86 \%$ were non-adherent. Older age (Spearman's rank correlation coefficient $(\mathrm{rho})=-0.157 ; p$-value $=0.025)$, and employed patients (rho $=-0.191 ; p$-value $=0.006$ ) were less likely to be non-adherent (e.g., ARMS score of $\geq 16$ ). Additionally, older age ( rho $=-0.207 ; p$-value $=0.003$ ) but not the employment status (rho $=-0.134 ; p$-value $=0.056$ ) was associated with lower total ARMS scores. On the other hand, male patients were more likely to be non-adherent in comparison to their female counterparts $(\mathrm{rho}=0.223 ; p$-value $=0.0014)$. Number of prescription medications (rho $=0.021 ; p$-value $=0.768)$, number of chronic health conditions ( $\mathrm{rho}=0.035$; $p$-value $=0.626)$, and health literacy $($ rho $=-0.106 ; p$-value $=0.132)$ were not associated with higher ARMS scores. Nonetheless, health literacy was negatively associated with the total ARMS score $($ rho $=-0.211 ; p$-value $=0.002)$, which means that those with adequate health literacy tend to have lower rates of non-adherence in comparison to their counterparts with limited health literacy levels.

\section{Discussion}

The ARMS is a widely used self-report questionnaire that has been used to assess medication adherence among diverse patient populations, particularly among older adults [26]. Additionally, it has been validated and culturally adapted to different languages, which makes it an attractive, easy to administer, free of charge, and reliable medication adherence scale [27-30]. However, the absence of a validated Arabic version of ARMS or other widely used and valid medication adherence scales that can be administered free of charge makes it hard to assess adherence to prescription medications among the Arabic-speaking patient population $[15,17,21]$. Therefore, translating and validating the ARMS into Arabic, which is a language spoken by more than 400 million people [44], should facilitate the assess- 
ment of medication adherence among Arabic-speaking patient population, particularly among those with chronic health conditions, such as diabetes and hypertension, which are prevalent in the Arab world [45-47]. This study is to the best of our knowledge the first to validate ARMS to Arabic among a cohort of patients with chronic health conditions in Saudi Arabia. The majority of the participants had diabetes and many of them had hypertension and dyslipidemia, which represents to a great extent the characteristics of patients with chronic health conditions in Saudi Arabia [46]. Additionally, the psychometric analysis showed good reliability and construct validity of the Arabic-ARMS.

The reliability of the Arabic-ARMS was assessed by two methods (test-retest and Cronbach's alpha methods), and in the two methods the Arabic-ARMS demonstrated good reliability [38-40]. The Cronbach's alpha for the 12-item Arabic-ARMS was 0.8 which is acceptable and comparable to the original scale and the other translated versions [26-30,48]. In addition, the two revealed factors in the factor analysis are similar to the ones identified in the original scale. The first factor consisted of eight items that assess patients' adherence to taking their prescription medications; whereas, the second factor consists of four items and assesses patients' adherence to filling their prescription medications. However, the variance explained by each factor and the item loadings differed from that found in the psychometric analysis of the original scale [26]. Kripalani et al. reported two factors in the original 12-item ARMS, factor 1 consisted of eight items that evaluated adherence to taking medications correctly, had an eigenvalue of 4.209 and explained $35.1 \%$ of the variance, and factor 2, consisted of four items that evaluated the participants' ability to refill medications on schedule, had an eigenvalue of 1.199 and explained $10.0 \%$ of the variance [26]. In this study, factor analysis identified the same number of factors identified in the original scale, however the distribution of items under the factors did not match that of the original scale. Additionally, the loadings of item number 3 and item number 9 are below cutoff point of $>0.4$ needed for any item to be attributed to a factor [49]. This is expected since the psychometric analyses of different validated versions of ARMS revealed different percentages of variance explained by these two factors [27-29]. Moreover, the Korean version identified an additional factor which represented the persistence with refilling medicines [28]. Additionally, the Chinese version omitted items 4 and 11 to accommodate the nature of their patient population, which resulted in higher Cronbach's alpha for factor $1(\alpha=0.90)$ and factor $2(\alpha=0.77)$ in comparison to the original scale [29]. Therefore, making appropriate adjustments to fit the patient population may generate better estimates and help in identifying unique characteristics of the targeted patient population leading to a better understanding of the reasons behind medication non-adherence.

The ARMS was originally developed among patients with low health literacy, which makes an attractive tool to assess medication non-adherence among patients with various levels of health literacy due to its high level of comprehensibility [26]. Marginal health literacy was associated with poor adherence to prescription medications in most published research studies that explored the association between medication non-adherence and different patient sociodemographic and medical characteristics [26,29,50]. Even though patients with limited health literacy were leaning toward being non-adherent (e.g., ARMS score $\geq 16$ ), the association between health literacy and Arabic-ARMS score was not significant. This can be due to the study's small sample or the fact that health literacy was assessed using the SILS which is not as reliable as other longer scales, such as Test of Functional Health Literacy (TOFHL) and Rapid Estimate of Adult Literacy in Medicine (REALM) [51]. However, adequate health literacy was negatively associated with the total ARMS score, which means that patients with adequate health literacy were more likely to adhere to their prescription medications. Therefore, different cut-off points for non-adherence using ARMS score should be explored.

Even though this is the first study to the best of our knowledge that translated and validated an Arabic version of the ARMS, several limitations must be acknowledged. First, patient recruitment was planned to end by March 2020, however, the COVID-19 pandemic has resulted in many appointments being postponed. Second, this is a single center 
study that explored the validity of a newly Arabic translated version of ARMS among patients with chronic health conditions. Therefore, the generalizability of its findings might be limited. Furthermore, since we included every 10th patient this might introduce some selection bias. Additionally, the scale was validated among a sample of patients who are largely Saudi. Thus, cultural and dialectal differences may make this Arabic translated version of ARMS not as comprehensible to non-Saudi patients as well as other Saudi patients from different geographic regions who were not represented in this study. Nonetheless, the scale was translated using Arabic terms that are understandable to anyone speaking the language. In addition, non-response bias cannot be excluded since not all patients who were invited to participate consented to participate and completed the questionnaire. Furthermore, the associations between different patient characteristics (e.g., beliefs about medications, patient medical and sociodemographic characteristics) and the ARMS score were not examined. In addition, the Arabic version of ARMS was not validated against other well-known medication adherence measures, such as pill count and medication possession ratio (MPR).

\section{Conclusions}

The findings of this study demonstrated good validity and reliability of the ArabicARMS, which makes it a feasible and accessible scale to many healthcare providers and researchers to assess medication adherence among patients with various health conditions. Future research should examine different cut-off points for non-adherence as well as crosscheck the results with other Arabic translated scales, such as MMAS-8. Furthermore, the psychometric properties of the Arabic-ARMS should be examined among larger samples of patients with various chronic health conditions, and in different healthcare settings and cultures. Moreover, the Arabic version of ARMS should be validated against other medication adherence measures, such as pill count. Additionally, examining the relationship between different predictors of medication non-adherence (e.g., depression, beliefs about medications, polypharmacy, and older age) and the Arabic version of ARMS score should be conducted.

Author Contributions: Concept and design, G.A., H.A., N.A. and Y.A.; acquisition, analysis, and/or interpretation of data, Y.A., G.A., H.A., N.A., Y.A.A. and I.S.; drafting of the manuscript, G.A., Y.A., I.S., A.J., T.H.A., M.A.B. and I.S.; Critical revision of the manuscript for important intellectual content, all authors; statistical analyses, Y.A. and I.S.; administrative, technical, and/or material support, Y.A., N.A., G.A., H.A., I.S., A.J., T.H.A., M.A.B. and Y.A.A. All authors have read and agreed to the published version of the manuscript.

Funding: The authors acknowledge the financial support received from the Researchers Supporting Project number (RSP-2021/16), King Saud University, Riyadh, Saudi Arabia.

Institutional Review Board Statement: The study protocol was approved by the ethics committee of King Saud University College of Medicine (E-19-3721), and the study was conducted according to the guidelines of the Declaration of Helsinki.

Informed Consent Statement: Informed consent was obtained from all subjects involved in the study, and no written consent for publication was required since no identifiable personal information are published.

Data Availability Statement: The data are available upon reasonable request from the corresponding author (Yazed AlRuthia).

Acknowledgments: The authors would like to thank Sunil Kripalani for granting us the permission to translate and validate the ARMS into Arabic. The copyright in ARMS is owned by Emory University.

Conflicts of Interest: The authors declare no conflict of interest. 


\section{Appendix A}

\section{The Adherence to Refills and Medications Scale (ARMS)}

\begin{tabular}{|c|c|c|c|c|}
\hline \multicolumn{5}{|c|}{ مقياس الإلتزام بتناول الدواء وإعادة التعبئة } \\
\hline $\begin{array}{l}\text { دائمأ } \\
\text { (4) }\end{array}$ & 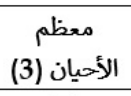 & الأحيان (2) & $\begin{array}{c}\text { إطلاقأ } \\
(1)\end{array}$ & \\
\hline$\square$ & $\square$ & $\square$ & $\square$ & 1. ما هو معدل نسيان تناول أدويتك؟؟ \\
\hline$\square$ & $\square$ & $\square$ & $\square$ & 2.ما هو معل إتخاذك قرار التوقف عن تناول أدويتك؟ \\
\hline$\square$ & $\square$ & $\square$ & $\square$ & 3. ما هو معدل نسيان تعبئة أدويتك؟؟ \\
\hline$\square$ & $\square$ & $\square$ & $\square$ & 4. ما هو معلدل نفاذ الأدوية لديك؟ \\
\hline$\square$ & $\square$ & $\square$ & $\square$ & 5.ما هو معدل عدم تناول أدويتك دون الرجوع للطبيب؟ \\
\hline$\square$ & $\square$ & $\square$ & $\square$ & 6. ما هو معلدل علدم تناول أدويتك عند شعورك بالتحسن؟ \\
\hline$\square$ & $\square$ & $\square$ & $\square$ & 7. ما هو معلد علدم تناول أدويتك عند شعورك بالمرض؟ \\
\hline$\square$ & $\square$ & $\square$ & $\square$ & 8. ما هو معدل عدم تناول أدويتك نتيجة الإهمال؟ \\
\hline$\square$ & $\square$ & $\square$ & $\square$ & 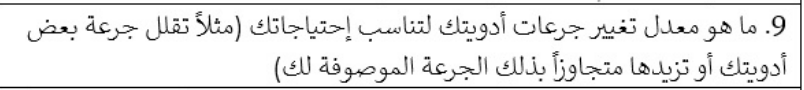 \\
\hline$\square$ & $\square$ & $\square$ & $\square$ & 10.ما هو معدل نسيان تناول أدويتك والتي من المغترض تناولها أكثر من مرة يوميأ؟ \\
\hline$\square$ & $\square$ & $\square$ & $\square$ & 11. ما هو معدل تأجيل تعبئة أدويتك بسبب تكلتها العالية؟ \\
\hline$\square$ & $\square$ & $\square$ & $\square$ & 12.ما هو معلدل تعبئة أدويتك قبل ملة من نفاذها؟ \\
\hline
\end{tabular}

Copyright (c) Emory University

\section{References}

1. Organization, W.H. Adherence to Long-Term Therapies: Evidence for Action; World Health Organization: Geneva, Switzerland, 2015.

2. Mohiuddin, A.K. Risks and reasons associated with medication non-adherence. J. Clin. Pharm. 2019, 1, 50-53.

3. Marcum, Z.A.; Sevick, M.A.; Handler, S.M. Medication nonadherence: A diagnosable and treatable medical condition. JAMA 2013, 309, 2105-2106. [CrossRef] [PubMed]

4. Kini, V.; Ho, P.M. Interventions to improve medication adherence: A review. JAMA 2018, 320, 2461-2473. [CrossRef] [PubMed]

5. Ho, P.M.; Bryson, C.L.; Rumsfeld, J.S. Medication adherence: Its importance in cardiovascular outcomes. Circulation 2009, 119, 3028-3035. [CrossRef]

6. Iuga, A.O.; McGuire, M.J. Adherence and health care costs. Risk Manag. Healthc. Policy 2014, 7, 35.

7. Zyoud, S.H.; Al-Jabi, S.W.; Sweileh, W.M.; Morisky, D.E. Relationship of treatment satisfaction to medication adherence: Findings from a cross-sectional survey among hypertensive patients in Palestine. Health Qual. Life Outcomes 2013, 11, 1-7. [CrossRef] [PubMed]

8. Ménard, S.; Jbilou, J.; Lauzier, S. Family caregivers' reported nonadherence to the controller medication of asthma in children in Casablanca (Morocco): Extent and associated factors. J. Asthma 2018, 55, 1362-1372. [CrossRef]

9. Altuwairqi, H.B. Barriers to medication adherence among cardiac patients following at King Fahad Medical City, Riyadh, Saudi Arabia. Saudi J. Health Sci. 2016, 5, 20. [CrossRef]

10. Khan, A.R.; Lateef, Z.N.A.-A.; Al Aithan, M.A.; Bu-Khamseen, M.A.; Al Ibrahim, I.; Khan, S.A. Factors contributing to noncompliance among diabetics attending primary health centers in the Al Hasa district of Saudi Arabia. J. Fam. Community Med. 2012, 19, 26. [CrossRef] [PubMed]

11. Rao, D.; Kekwaletswe, T.C.; Hosek, S.; Martinez, J.; Rodriguez, F. Stigma and social barriers to medication adherence with urban youth living with HIV. AIDS Care 2007, 19, 28-33. [CrossRef] [PubMed]

12. Blashill, A.J.; Perry, N.; Safren, S.A. Mental health: A focus on stress, coping, and mental illness as it relates to treatment retention, adherence, and other health outcomes. Curr. HIV/AIDS Rep. 2011, 8, 215-222. [CrossRef] [PubMed]

13. Fernandez-Lazaro, C.I.; Adams, D.P.; Fernandez-Lazaro, D.; Garcia-González, J.M.; Caballero-Garcia, A.; Miron-Canelo, J.A. Medication adherence and barriers among low-income, uninsured patients with multiple chronic conditions. Res. Soc. Adm. Pharm. 2019, 15, 744-753. [CrossRef] [PubMed]

14. Pasina, L.; Brucato, A.; Falcone, C.; Cucchi, E.; Bresciani, A.; Sottocorno, M.; Taddei, G.C.; Casati, M.; Franchi, C.; Djade, C.D.; et al. Medication non-adherence among elderly patients newly discharged and receiving polypharmacy. Drugs Aging 2014, 31, 283-289. [CrossRef] [PubMed]

15. Lam, W.Y.; Fresco, P. Medication adherence measures: An overview. BioMed Res. Int. 2015, 2015, 1-12. [CrossRef]

16. Kreys, E. Measurements of medication adherence: In search of a gold standard. J. Clin. Pathw. 2016, 2, 43-47.

17. Anghel, L.A.; Farcas, A.M.; Oprean, R.N. An overview of the common methods used to measure treatment adherence. Med. Pharm. Rep. 2019, 92, 117. [CrossRef] [PubMed] 
18. Nguyen, T.-M.-U.; Caze, A.L.; Cottrell, N. What are validated self-report adherence scales really measuring?: A systematic review. Br. J. Clin. Pharmacol. 2014, 77, 427-445. [CrossRef] [PubMed]

19. Zullig, L.L.; Mendys, P.; Bosworth, H.B. Medication adherence: A practical measurement selection guide using case studies. Patient Educ. Couns. 2017, 100, 1410-1414. [CrossRef]

20. Stirratt, M.J.; Dunbar-Jacob, J.; Crane, H.M.; Simoni, J.; Czajkowski, S.; Hilliard, M.; Aikens, J.E.; Hunter, C.M.; Velligan, D.I.; Huntley, K.; et al. Self-report measures of medication adherence behavior: Recommendations on optimal use. Transl. Behav. Med. 2015, 5, 470-482. [CrossRef]

21. Ashur, S.; Shamsuddin, K.; Shah, S.; Bosseri, S.; Morisky, D. Reliability and known-group validity of the Arabic version of the 8-item Morisky Medication Adherence Scale among type 2 diabetes mellitus patients. East. Mediterr. Health J. 2015, 21, 722-728. [CrossRef] [PubMed]

22. Lavsa, S.M.; Holzworth, A.; Ansani, N.T. Selection of a validated scale for measuring medication adherence. J. Am. Pharm. Assoc. 2011, 51, 90-94. [CrossRef] [PubMed]

23. Karademir, M.; Koseoglu, I.H.; Vatansever, K.; Van Den Akker, M. Validity and reliability of the Turkish version of the Hill-Bone compliance to high blood pressure therapy scale for use in primary health care settings. Eur. J. Gen. Pract. 2009, 15, $207-211$. [CrossRef] [PubMed]

24. Ranasinghe, P.; Jayawardena, R.; Katulanda, P.; Constantine, G.R.; Ramanayake, V.; Galappatthy, P. Translation and validation of the sinhalese version of the brief medication questionnaire in patients with diabetes mellitus. J. Diabetes Res. 2018, $2018,1-7$. [CrossRef] [PubMed]

25. Dong, X.-F.; Liu, Y.-J.; Wang, A.-X.; Lv, P.-H. Psychometric properties of the Chinese version of the self-efficacy for appropriate medication use scale in patients with stroke. Patient Prefer. Adherence 2016, 10, 321.

26. Kripalani, S.; Risser, J.; Gatti, M.E.; Jacobson, T.A. Development and evaluation of the Adherence to Refills and Medications Scale (ARMS) among low-literacy patients with chronic disease. Value Health 2009, 12, 118-123. [CrossRef]

27. Gökdoğan, F.; Kes, D. Validity and reliability of the Turkish adherence to refills and medications scale. Int. J. Nurs. Pract. 2017, 23, e12566. [CrossRef] [PubMed]

28. Kim, C.-J.; Park, E.; Schlenk, E.A.; Kim, M.; Kim, D.J. Psychometric evaluation of a Korean version of the Adherence to Refills and Medications Scale (ARMS) in adults with type 2 diabetes. Diabetes Educ. 2016, 42, 188-198. [CrossRef]

29. Chen, Y.-J.; Chang, J.; Yang, S.-Y. Psychometric evaluation of Chinese version of Adherence to Refills and Medications Scale (ARMS) and blood-pressure control among elderly with hypertension. Patient Prefer. Adherence 2020, 14, 213. [CrossRef] [PubMed]

30. Lomper, K.; Chabowski, M.; Chudiak, A.; Białoszewski, A.; Dudek, K.; Jankowska-Polańska, B. Psychometric evaluation of the Polish version of the Adherence to Refills and Medications Scale (ARMS) in adults with hypertension. Patient Prefer. Adherence 2018, 12, 2661. [CrossRef] [PubMed]

31. Morris, N.S.; MacLean, C.D.; Chew, L.D.; Littenberg, B. The Single Item Literacy Screener: Evaluation of a brief instrument to identify limited reading ability. BMC Fam. Pract. 2006, 7, 1-7. [CrossRef]

32. Al-Jumaili, A.A.; Al-Rekabi, M.D.; Sorofman, B. Evaluation of instruments to assess health literacy in Arabic language among Iraqis. Res. Soc. Adm. Pharm. 2015, 11, 803-813. [CrossRef]

33. Anthoine, E.; Moret, L.; Regnault, A.; Sébille, V.; Hardouin, J.-B. Sample size used to validate a scale: A review of publications on newly-developed patient reported outcomes measures. Health Qual. Life Outcomes 2014, 12, 1-10. [CrossRef]

34. Osborne, J.W.; Costello, A.B. Sample size and subject to item ratio in principal components analysis. Pract. Assess. Res. Eval. 2004, $9,11$.

35. Ledesma, R.D.; Valero-Mora, P. Determining the number of factors to retain in EFA: An easy-to-use computer program for carrying out parallel analysis. Pract. Assess. Res. Eval. 2007, 12, 2.

36. Xia, Y.; Yang, Y. RMSEA, CFI, and TLI in structural equation modeling with ordered categorical data: The story they tell depends on the estimation methods. Behav. Res. Methods 2019, 51, 409-428. [CrossRef] [PubMed]

37. Williams, B.; Onsman, A.; Brown, T. Exploratory factor analysis: A five-step guide for novices. Australas. J. Paramed. 2010, 8, 1-13. [CrossRef]

38. Liljequist, D.; Elfving, B.; Skavberg Roaldsen, K. Intraclass correlation-A discussion and demonstration of basic features. PLoS ONE 2019, 14, e0219854. [CrossRef] [PubMed]

39. Perinetti, G. StaTips Part IV: Selection, interpretation and reporting of the intraclass correlation coefficient. South Eur. J. Orthod. Dentofac. Res. 2018, 5, 3-5. [CrossRef]

40. Ursachi, G.; Horodnic, I.A.; Zait, A. How reliable are measurement scales? External factors with indirect influence on reliability estimators. Procedia Econ. Financ. 2015, 20, 679-686. [CrossRef]

41. Fornell, C.; Larcker, D.F. Evaluating structural equation models with unobservable variables and measurement error. J. Mark. Res. 1981, 18, 39-50. [CrossRef]

42. Ab Hamid, M.; Sami, W.; Sidek, M.M. Discriminant validity assessment: Use of Fornell \& Larcker criterion versus HTMT criterion. Paper presented at: J. Phys. Conf. Ser. 2017, 890, 012163.

43. Association WM. World Medical Association Declaration of Helsinki. Ethical principles for medical research involving human subjects. Bull. World Health Organ. 2001, 79, 373.

44. Kamusella, T.D. The Arabic language: A Latin of modernity? J. Natl. Mem. Lang. Politics 2017, 11, 117-145. [CrossRef]

45. Abuyassin, B.; Laher, I. Diabetes epidemic sweeping the Arab world. World J. Diabetes 2016, 7, 165-174. [CrossRef] [PubMed] 
46. Tyrovolas, S.; El Bcheraoui, C.; Alghnam, S.A.; Alhabib, K.F.; Almadi, M.A.H.; Al-Raddadi, R.M.; Bedi, N.; Tantawi, M.E.; Krish, V.S.; Memish, Z.A.; et al. The burden of disease in Saudi Arabia 1990-2017: Results from the Global Burden of Disease Study 2017. Lancet Planet. Health 2020, 4, e195-e208. [CrossRef]

47. Mokdad, A.H.; Jaber, S.; Aziz, M.I.A.; AlBuhairan, F.; AlGhaithi, A.; AlHAmad, N.M.; Al-Hooti, S.N.; Al-Jasari, A.; AlMazroa M.A.; AlQasmi, A.M.; et al. The state of health in the Arab world, 1990-2010: An analysis of the burden of diseases, injuries, and risk factors. Lancet 2014, 383, 309-320. [CrossRef]

48. Tavakol, M.; Dennick, R. Making sense of Cronbach's alpha. Int. J. Med. Educ. 2011, 2, 53-55. [CrossRef]

49. Cutillo, L. Parametric and multivariate methods. In Encyclopedia of Bioinformatics and Computational Biology; Ranganathan, S., Nakai, K., Schonbach, C., Eds.; Elsevier: Amsterdam, Netherlands, 2019; pp. 738-746. [CrossRef]

50. Lee, Y.-M.; Yu, H.Y.; You, M.-A.; Son, Y.-J. Impact of health literacy on medication adherence in older people with chronic diseases. Collegian 2017, 24, 11-18. [CrossRef]

51. Tian, C.Y.; Xu, R.H.; Mo, P.K.-H.; Dong, D.; Wong, E.L.-Y. Generic health literacy measurements for adults: A scoping review. Int. J. Environ. Res. Public Health 2020, 17, 7768. [CrossRef] [PubMed] 